\title{
Effect of ovulation and sperm motility on the migration of rabbit spermatozoa to the site of fertilization
}

\author{
J. W. Overstreet* and G. W. Cooper \\ Laboratory of Reproductive Biology, Department of Obstetrics and Gynecology, \\ Cornell University Medical College, 1300 York Avenue, New York, \\ New York 10021, U.S.A.
}

\begin{abstract}
Summary. Few spermatozoa were present in the ampullae of females $12 \mathrm{~h}$ after intravaginal artificial insemination (AI) when there was no ovulation-inducing stimulus. When ovulation was induced, sperm distributions in the female tract $12 \mathrm{~h}$ after AI did not differ from those observed $12 \mathrm{~h}$ after natural mating. The number of spermatozoa in the oviductal isthmus was similar in all 3 groups as was the percentage of isthmic spermatozoa exhibiting 'activated' motility. When fertile mating was delayed for 8 or $12 \mathrm{~h}$ after coitus with a vasectomized male (i.e. $2 \mathrm{~h}$ before or after ovulation), spermatozoa were not present in the ampulla $4 \mathrm{~h}$ later. The numbers of spermatozoa recovered from the cranial isthmus after delayed matings and $12 \mathrm{~h}$ after natural matings did not differ, but after delayed matings the motility of isthmic spermatozoa was non-progressive or poorly progressive and none exhibited 'activated' motility. Flagellar activity of isthmic spermatozoa recovered $4 \mathrm{~h}$ after delayed matings and after natural matings was similarly depressed. These observations indicate that sperm ascent to the tubal ampulla in the sustained phase of transport, though enhanced by ovulation, must also depend on changes in flagellar activity and a specific pattern of motility, both of which appear only after spermatozoa have resided for more than $4 \mathrm{~h}$ in the female tract.
\end{abstract}

\section{Introduction}

Rabbit spermatozoa enter the ampulla of the oviduct in significant numbers only during two limited intervals after mating. The first, the rapid-transport phase, begins immediately after coitus with the passive transfer of spermatozoa to the infundibulum and peritoneal cavity and ends within minutes of insemination. Most of these spermatozoa are non-motile and pass into the peritoneal cavity before ovulation (Overstreet \& Cooper, 1978). Spermatozoa are then excluded from the upper oviduct until the peri-ovulatory period when the second phase of sperm ascent begins (Harper, 1973a, b; Overstreet, Cooper \& Katz, 1978): the spermatozoa then recovered from the cranial isthmus and ampulla are vigorously motile and many display a pattern of 'activated' motility characterized by alternating cycles of vigorous non-progressive and forward-progressive motility. Only a limited number of those spermatozoa passing to the site of fertilization are retained there, the remainder probably pass into the peritoneal cavity (Overstreet et al., 1978). The present report is on the control of the second phase of sperm ascent to the ampulla and its relationship to sperm capacitation in the rabbit (Bedford, 1970; Austin, 1975).

\footnotetext{
* Present address: Department of Human Anatomy, School of Medicine, University of California, Davis, California 95616, U.S.A.
} 


\section{Materials and Methods}

\section{Experiments}

Experiment 1. To determine the distribution of spermatozoa in the female tract in the absence of ovulation, 6 New Zealand White does were each artificially inseminated per vaginam (AI) with a single ejaculate (Adams, 1962). The does were tested for behavioural oestrus by placing them with a single ejaculate (Adams, 1962). The does were tested for behavioural oestrus by placing them with a vasectomized buck and observing lordosis. The buck was allowed to mount but animal were included with those from two others that were induced to ovulate by mating once with a vasectomized buck (sterile coitus) immediately before AI. Sperm transport in these two groups of animals (AI with ovulation and AI without ovulation) was compared with that occurring after natural mating (Overstreet et al., 1978). Spermatozoa were recovered $12 \mathrm{~h}$ after insemination from the entire reproductive tracts of these 8 females.

Experiment 2. The distribution of spermatozoa in the tract after delayed mating was determined in 4 does mated once to a fertile buck $8 \mathrm{~h}$ after sterile coitus, and in 4 does mated $12 \mathrm{~h}$ after sterile coitus. Does mated $8 \mathrm{~h}$ after sterile coitus were still in behavioural oestrus, but 2 of the 4 presented to a fertile buck $12 \mathrm{~h}$ after sterile coitus refused service and had to be forced mated. Spermatozoa were recovered from the tracts of all 8 does $4 \mathrm{~h}$ after the fertile mating, i.e. 12 or $16 \mathrm{~h}$ after sterile coitus. Sterile coitus was used instead of gonadotrophin injection to induce ovulation because changes in the levels of ovarian steroids after coitus may control uterine and oviductal contractions (Fuchs, 1974), and exogenous gonadotrophins appear to alter the patterns of preovulatory steroid secretion (Spilman \& Wilks, 1976).

\section{Sperm recovery, counts and analyses}

The methods of recovery and quantitative evaluation of spermatozoa from the cervix, uterus, 4 regions of the oviduct, the ovarian surface and fimbria of the rabbit have been described in detail elsewhere (Overstreet \& Cooper, 1978; Overstreet et al., 1978). Sperm recovery and evaluation were carried out at $37^{\circ} \mathrm{C}$ in a controlled environment room. The total number of spermatozoa present in the cervix and uterus was estimated by counting the number recovered in two successive $1 \mathrm{ml}$ flushes. The medium for the initial flush was $5 \%(\mathrm{v} / \mathrm{v})$ rabbit serum

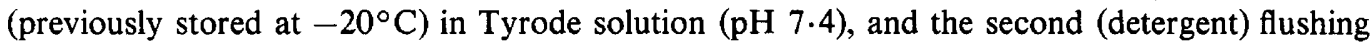
medium was $0.5 \%(\mathrm{w} / \mathrm{v})$ sodium dodecyl sulphate (SDS: lauryl sulphate: Sigma) in distilled water. Spermatozoa were recovered from the tubal isthmus by flushing $10 \mu \mathrm{l}$ serum-Tyrode through each segment into a micropipette, followed by $0.5 \mathrm{ml}$ SDS. The spermatozoa in the serum-Tyrode sample were assessed for motility, and sperm numbers in both flushings were combined to estimate the total number present. The ampullar segments were flushed into micropipettes with $10 \mu \mathrm{l}$ serum-Tyrode followed by $0.25 \mathrm{ml} 0.9 \%(\mathrm{w} / \mathrm{v}) \mathrm{NaCl}$ and then $0.25 \mathrm{ml} \mathrm{SDS}$. Ova were removed from the first two flushings and were fixed in acetic:ethanol $(3: 1, \mathrm{v} / \mathrm{v})$ and stained with lacmoid (Chang, 1952) to assess sperm penetration into the vitellus. The motility of spermatozoa in the serum-Tyrode was assessed and the total numbers of spermatozoa present were estimated from the number in all three flushings plus those associated with the ova and cumulus. Spermatozoa were recovered from the fimbrial and ovarian surfaces by washing each with $0.5 \mathrm{ml}$ SDS. Spermatozoa in the serum-Tyrode sample which showed any sign of flagellar activity were scored as motile. Particular note was made of oviductal spermatozoa displaying alternating vigorous non-progressive and forward progressive motility. The membranes of each sperm head were scored as intact or disrupted (Overstreet \& Cooper, 1975).

Because of the small sample sizes, statistical analysis of the data was by non-parametric methods. The Kruskal-Wallis one-way analysis of variance by ranks (Hollander \& Wolfe, 1973) was used to assess variations in central tendency, with paired comparisons therein being assessed by the Kruskal-Wallis rank series. A 5\% significance level was applied throughout. 
Table 1. Distribution of rabbit spermatozoa in the reproductive tract of females $12 \mathrm{~h}$ after insemination, in the presence or absence of ovulation (Exp. 1)

\begin{tabular}{lccc}
\hline & \multicolumn{2}{c}{ Artificial insemination } & Natural mating \\
\cline { 2 - 4 } & Without ovulation & With ovulation & 5 \\
with ovulation*
\end{tabular}

* Data from Overstreet et al. (1978).

$\dagger$ The median total numbers of spermatozoa associated with the ova and cumulus in each animal with the range in parentheses.

$\ddagger$ Median total numbers of spermatozoa/animal recovered in serum-Tyrode and saline + SDS flushings of each region with the range in parentheses.

$\S$ These values are significantly different from those of rabbits which did not ovulate.

\section{Results}

The effect of ovulation on the distribution and motility of spermatozoa within the oviduct

No significant differences were found in the number and distribution of spermatozoa below the ampulla $12 \mathrm{~h}$ after semen deposition by AI or mating, irrespective of whether the AI females had ovulated or not. Significantly fewer spermatozoa were present, however, in the ampulla of the 5 AI females which did not ovulate (Table 1). The flagellar activity of isthmic spermatozoa recovered from the ovulatory and non-ovulatory AI females was similar (Table 2). In the caudal isthmus flagellation was sluggish and no more than $6 \%$ of the spermatozoa displayed 'activated' motility, while spermatozoa recovered from the cranial isthmus were vigorously motile and as many as $64 \%$ exhibited 'activated' movement.

Table 2. Motility of rabbit spermatozoa recovered from the cranial and caudal segments of the isthmus $12 \mathrm{~h}$ after insemination, in the presence or absence of ovulation (Exp. 1)

\begin{tabular}{|c|c|c|c|}
\hline & \multicolumn{2}{|c|}{ Artificial insemination } & \multirow{2}{*}{$\begin{array}{l}\text { Natural mating } \\
\text { with ovulation }\end{array}$} \\
\hline & Without ovulation & With ovulation & \\
\hline No. of animals & 5 & 3 & 5 \\
\hline \multicolumn{4}{|l|}{ Cranial isthmus } \\
\hline No. of animals with spermatozoa & 4 & 3 & 5 \\
\hline$\%$ Motility ${ }^{\dagger}$ & $72(40-100)$ & $94(88-100)$ & $92(88-100)$ \\
\hline$\%$ Activation $\ddagger$ & $21(0-64)$ & $29(0-53)$ & $33(0-60)$ \\
\hline \multicolumn{4}{|l|}{ Caudal isthmus } \\
\hline No. of animals with spermatozoa & 5 & 3 & 5 \\
\hline$\%$ Motility $\dagger$ & $70(58-80)$ & $61(54-76)$ & $61(34-88)$ \\
\hline$\%$ Activation $\ddagger$ & $3(0-6)$ & $1(0-2)$ & $3(0-7)$ \\
\hline
\end{tabular}

$\uparrow$ Median percentage of motile spermatozoa/animal (range).

$\ddagger$ Median percentage of motile spermatozoa/animal with a mixed pattern of vigorous non-progressive and forward-progressive movement (range). 
Table 3. Sperm transport and fertilization in rabbits mated during the periovulation period (see text) in comparison with that in naturally mated rabbits (Exp. 2)

\begin{tabular}{|c|c|c|c|c|}
\hline & \multicolumn{2}{|c|}{ Delayed mating } & \multicolumn{2}{|c|}{ Natural mating* } \\
\hline & $\begin{array}{l}\text { Recovery } 4 \text { h p.c. } \\
\text { Ovulation }-2 \text { h p.c. }\end{array}$ & $\begin{array}{l}\text { Recovery } 4 \text { h p.c. } \\
\text { Ovulation }+2 \text { h p.c. }\end{array}$ & $\begin{array}{l}\text { Recovery } 12 \mathrm{~h} p . c . \\
\text { Ovulation } 10 \mathrm{~h} p . c .\end{array}$ & Recovery 4 h p.c. \\
\hline No. of animals & 4 & 4 & 5 & 5 \\
\hline \multicolumn{5}{|l|}{ Fertilization } \\
\hline No. of ova & 29 & 32 & 36 & 0 \\
\hline$\%$ Fertilized & 0 & 0 & 53 & - \\
\hline No. of spermato- & & & & \\
\hline $\begin{array}{l}\text { zoa/ova } \\
\text { (median and } \\
\text { range) }\end{array}$ & 0 & 0 & $68(25-636)$ & 一 \\
\hline \multicolumn{5}{|l|}{ Sperm recovery ${ }^{\dagger}$} \\
\hline Fimbria and ovary & 0 & $211(0-994)$ & $12(0-504)$ & $0(0-110)$ \\
\hline Cranial ampulla & 0 & $2(0-160)$ & $\ddagger 17(1-172)$ & $1(0-1)$ \\
\hline Caudal ampulla & 0 & 0 & $\ddagger 75(2-32)$ & 0 \\
\hline Cranial isthmus & $14(0-30)$ & $32(0-313)$ & $42(1-145)$ & $5(0-21)$ \\
\hline Caudal isthmus & $1.14 \times 10^{4}(0.11-3 \cdot 21)$ & $8.14 \times 10^{3}(5.09-11.53)$ & $1.12 \times 10^{4}(0.09-4.41)$ & $\ddagger 1.32 \times 10^{3}(0.04-5.23)$ \\
\hline Uterus & $1.00 \times 10^{6}(0.07-1.87)$ & $1.22 \times 10^{6}(0.29-2.33)$ & $4.42 \times 10^{6}(0.78-8.38)$ & $1.45 \times 10^{6}(0.02-2.24)$ \\
\hline Cervix & $2.53 \times 10^{7}(0.06-4.16)$ & $1.74 \times 10^{7}(0.37-3.81)$ & $0.21 \times 10^{7}(0.12-1.81)$ & $2.03 \times 10^{7}(0.03-3.22)$ \\
\hline
\end{tabular}

* Data from Overstreet et al. (1978).

$\dagger$ Median total number of spermatozoa/female recovered in the serum-Tyrode and saline + SDS flushings of each region with the range in parentheses.

$\ddagger$ These values are significantly different from the others in that row.

\section{The location and motility of oviductal spermatozoa after delayed mating}

Motile spermatozoa were found only in the isthmus of oviducts examined $4 \mathrm{~h}$ after delayed matings: the median number recovered was significantly greater than at $4 \mathrm{~h}$ after natural mating and equalled that present in the isthmus $12 \mathrm{~h}$ after natural mating (Table 3). Ova in cumulus were recovered after delayed mating from the caudal ampulla but none was penetrated (Table 3 ). The flagellar activity of spermatozoa recovered from the cranial isthmus after delayed matings clearly differed from that seen $12 \mathrm{~h}$ after natural mating (Table 4). Sperm motility in both regions

Table 4. Motility of oviductal spermatozoa recovered from rabbits mated during the periovulation period (see text) in comparison with that in naturally mated rabbits (Exp. 2)

\begin{tabular}{|c|c|c|c|c|}
\hline & \multicolumn{2}{|c|}{ Delayed mating } & \multicolumn{2}{|c|}{ Natural mating } \\
\hline & $\begin{array}{l}\text { Recovery } 4 \text { h p.c. } \\
\text { Ovulation }-2 \text { h p.c. }\end{array}$ & $\begin{array}{l}\text { Recovery } 4 \mathrm{~h} p . c . \\
\text { Ovulation }+2 \mathrm{~h} p . c .\end{array}$ & $\begin{array}{l}\text { Recovery } 12 \mathrm{~h} \text { p.c. } \\
\text { Ovulation } 10 \mathrm{~h} \text { p.c. }\end{array}$ & Recovery $4 \mathrm{~h} p . c$. \\
\hline No. of animals & 4 & 4 & 5 & 5 \\
\hline \multicolumn{5}{|l|}{ Cranial isthmus } \\
\hline $\begin{array}{l}\text { No. of animals with } \\
\text { spermatozoa }\end{array}$ & 2 & 3 & 5 & 3 \\
\hline \%Motility ${ }^{\dagger}$ & 64,97 & $82(66-84)$ & $92(88-100)$ & $81(67-100)$ \\
\hline \%Activation $\ddagger$ & 0 & 0 & $\S 33(0-60)$ & 0 \\
\hline \multicolumn{5}{|l|}{ Caudal isthmus } \\
\hline $\begin{array}{l}\text { No. of animals with } \\
\text { spermatozoa }\end{array}$ & 4 & 4 & 5 & 5 \\
\hline \%otility $\uparrow$ & $72(69-86)$ & $71(62-79)$ & $61(34-88)$ & $76(57-88)$ \\
\hline \%Activation $\ddagger$ & 0 & 0 & $\S 3(0-7)$ & 0 \\
\hline
\end{tabular}

$\dagger$ Median percentage of motile spermatozoa/animal (range).

$\ddagger$ Median percentage of motile spermatozoa/animal with a mixed pattern of vigorous non-progressive and forwardprogressive movement (range).

$\S$ These values are significantly different from the others in that row. 
of the isthmus was sluggish and poorly progressive after delayed mating, as was the case $4 \mathrm{~h}$ after natural mating. In contrast, spermatozoa recovered from the cranial isthmus $12 \mathrm{~h}$ after natural mating were vigorously motile and many displayed 'activated' movement (Table 4).

Immotile spermatozoa with visibly disrupted head membranes were recovered from the cranial ampulla, ovary and fimbria of the left sides of the two does force mated $2 \mathrm{~h}$ after ovulation (Table 3). No spermatozoa were found in these regions in the $8 \mathrm{~h}$ delayed mating group or in the 2 does which mated voluntarily $12 \mathrm{~h}$ after sterile coitus (Table 3 ).

\section{Discussion}

The final ascent of rabbit spermatozoa to the ampulla at the time of fertilization appears to depend on ovulation-associated alterations in the physiology of the female tract, and on changes in the pattern of sperm motility. The present results suggest that sperm migration through the cranial regions of the isthmus is restricted during the sustained phase of sperm transport, and that this restriction is relaxed near the time of ovulation. When spermatozoa are 'activated' in the absence of ovulation, most are retained in the cranial isthmus and are unable to ascend to the ampulla. However, if ovulation occurs before spermatozoa become 'activated' they do not reach the ampulla, so vigorous flagellar activity must also be required. Our previous observations on the location of spermatozoa in the tract, before and after ovulation, demonstrate that sperm migration beyond the isthmus normally coincides with ovulation (Overstreet et al., 1978) and support earlier interpretations (Harper, 1973a) that ovulation and the tubal ascent of spermatozoa are co-ordinated events. The failure of spermatozoa to enter the ampulla in the absence of ovulation cannot be attributed to a limitation on the number available for passage, because the median number in the isthmus $12 \mathrm{~h}$ after $\mathrm{AI}$ is comparable to that after natural mating (Table 1). Nor does flagellar activity appear to be limiting because the sperm motility in these does was indistinguishable from that in mated females (Table 2), and in both groups many spermatozoa from the cranial isthmus exhibited 'activated' motility. The mechanism by which sperm ascent is normally synchronized with ovulation may depend on changes in the amplitude and frequency of oviductal contractions (Salomy \& Harper, 1971; Talo, 1974), which are probably regulated systemically by changes in ovarian steroid secretion before ovulation (Hilliard, Hayward \& Sawyer, 1964; Hilliard, Scaramuzzi, Pang, Penardi \& Sawyer, 1974; Waterston \& Mills, 1976). Although the products of ovulation may also stimulate sperm ascent directly (Harper, 1973b), it is unlikely that they are the only mediator, for we have observed this migration as early as $2 \mathrm{~h}$ before the expected time of ovulation in rabbits (Overstreet et al., 1978).

The distribution of spermatozoa in the oviduct after delayed mating shows that neither ovulation-associated changes in tubal contractility nor the products of ovulation can induce sperm ascent to the ampulla when activation has not occurred. Large numbers of spermatozoa reach the caudal oviduct during the periovulatory period when fertile mating is delayed for 8 or $12 \mathrm{~h}$ after sterile coitus, but they remain in the isthmus and do not associate with ova (Table 3 ). Spermatozoa recovered from the cranial isthmus of ovulating animals $12 \mathrm{~h}$ after natural mating were vigorously motile, whereas after delayed mating they were weakly motile with poor progression (Table 4). Failure of spermatozoa to ascend to the ampulla within $4 \mathrm{~h}$ after delayed mating, therefore, may reflect their depressed flagellar activity in the isthmus. This appears to be a time-dependent phenomenon unrelated to the hormonal state of the female, because the motility of spermatozoa from the caudal and cranial isthmus is similarly depressed at $4 \mathrm{~h}$ after natural or delayed mating. Sperm retention and ascent in the rabbit oviduct may be effected by reversible suppression and reactivation of motility in the isthmic reservoir, or by an irreversible immobilization of isthmic spermatozoa, coupled with a supervening passage of spermatozoa from the uterus to the cranial oviduct near the time of ovulation (see Overstreet \& Katz, 1977, for further discussion of these possibilities). 
Evidence obtained in a variety of mammals suggests that sperm transport to the oviduct is accelerated when insemination takes place soon after ovulation (rat: Braden \& Austin, 1954; hamster: Yanagimachi \& Chang, 1963; guinea-pig: Yanagimachi \& Mahi, 1976; sheep: Dauzier \& Wintenberger, 1952; du Mesnil du Buisson \& Dauzier, 1955). The distribution of rabbit spermatozoa in the female tract when transport took place after ovulation (Table 3) agrees with the findings of Turnbull (1966) that the ratio of oviductal to uterine spermatozoa is increased after delayed matings. However, our finding that no spermatozoa reach the site of fertilization within $4 \mathrm{~h}$ of delayed mating conflicts with previous reports of rabbit sperm recovery from the ampulla within $4 \mathrm{~h}$ after natural and delayed matings (Braden, 1953; Braden \& Austin, 1954; Turnbull, 1966). The spermatozoa recovered from the ampulla during the first few hours after mating are derived exclusively from the non-viable residuum of the rapid-transit phase of transport, and are located near the infundibulum rather than the site of fertilization (Overstreet \& Cooper, 1978). In the present experiments immotile spermatozoa with disrupted head membranes were recovered from the cranial ampulla of two does mated $2 \mathrm{~h}$ after ovulation. The non-viability of these spermatozoa, their absence from the caudal ampulla and their unilateral location in the left oviduct and on the fimbria and ovary of this side are all characteristic of the rapid-transit phase of sperm transport in the rabbit (Overstreet \& Cooper, 1978). Previous reports of sperm recovery from the ampulla within $4 \mathrm{~h}$ of insemination may reflect the recovery of these non-viable spermatozoa, the redistribution of tubal contents by post-mortem contractions of the tract, or flushing procedures resulting in contamination of the ampullar contents. The methods employed in the present study permit the localization of spermatozoa and ova in discrete regions of the oviduct and avoid such artefacts.

Observations of infertility (Hammond, 1934; Adams \& Chang, 1962) and decreased fertilization rates after delayed mating (Austin \& Braden, 1954; Turnbull, 1966) have shown 4-5 $\mathrm{h}$ to be the minimal time required in vivo for capacitation of rabbit spermatozoa. A similar interval also appears to be required for the appearance of actively motile spermatozoa in the ampulla of this species. Since motile rabbit spermatozoa with missing or altered acrosomes are detected in the oviduct at $6 \mathrm{~h}$ after insemination (unpublished), we believe it likely that the membrane changes of capacitation which precede the acrosome reaction must also produce motility changes required for sperm ascent to the site of fertilization.

We thank Dr D. F. Katz for performing the statistical analysis of the data, and Dr J. M. Bedford for his advice during the preparation of this report. We also thank Ms Renee Smith for typing the manscript. The research was supported by NIH Grant HD-09215 and a grant from the Ford Foundation.

\section{References}

Adams, C.E. (1962) Artifical insemination in rodents. In The Semen of Animals and Artifical Insemination, Ch. 18, pp. 316-330. Ed. J. P. Maule. Commonwealth Agricultural Bureau, Farnham.

Adams, C.E. \& Chang, M.C. (1962) The effect of delayed mating on fertilization in the rabbit. $J$. exp. Zool. 151, 155-158.

Austin, C.R. (1975) Membrane fusion events in fertilization. J. Reprod. Fert. 44, 155-166.

Austin, C.R. \& Braden, A.W.H. (1954) Time relations and their significance in the ovulation and penetration of eggs in rats and rabbits. Aust. J. biol. Sci. 7, 179-194.

Bedford, J.M. (1970) Sperm capacitation and fertilization in mammals. Biol. Reprod., Suppl. 2, 128-158.
Braden, A.W.H. (1953) Distributions of sperms in the genital tract of the female rabbit after coitus. A ust. J. biol. Sci. 6, 693-705.

Braden, A.W.H. \& Austin, C.R. (1954) The numbers of sperms about the eggs in mammals and its significance for normal fertilization. Aust. J. biol. Sci. 7, 543-551.

Chang, M.C. (1952) Fertilizability of rabbit ova and the effects of temperature in vitro on their subsequent fertilization and activation in vivo. J. exp. Zool. 121, $351-370$.

Dauzier, L. \& Wintenberger, S. (1952) Recherches sur la fécondation chez les Mammifères: la remontée des spermatozoides dans le tractus génital de la brebis. C r. Séanc. Soc. Biol. 146, 67-70. 
du Mesnil du Buisson, F. \& Dauzier, L. (1955) Distribution et résorption du sperme dans le tractus génital de la Truie: survie de spermatozoides. Annls. Endocr. 16, 413-422.

Fuchs, A.R. (1974) Regulation of uterine activity during gestation and parturition in rabbits and rats. In Physiology and Genetics of Reproduction, Part B, pp. 403-422. Eds E. M. Coutinho \& F. Fuchs. Plenum Press, New York.

Hammond, J. (1934) The fertilization of rabbit ova in relation to time. J. exp. Biol. 11, 140-161.

Harper, M.J.K. (1973a) Relationship between sperm transport and penetration of eggs in the rabbit oviduct. Biol. Reprod. 8, 441-450.

Harper, M.J.K. (1973b) Stimulation of sperm movement from the isthmus to the site of fertilization in the rabbit oviduct. Biol. Reprod. 8, 369-377.

Hilliard, J., Hayward, J.N. \& Sawyer, C.H. (1964) Post coital patterns of secretion of pituitary gonadotropin and ovarian progestin in the rabbit. Endocrinology 75, 957-963.

Hilliard, J., Scaramuzzi, R.J., Pang, C.M., Penardi, R. \& Sawyer, C.H. (1974) Testosterone secretion by rabbit ovary in vivo. Endocrinology 94, 267-271.

Hollander, M. \& Wolfe, D.A. (1973) Nonparametric Statistical Methods. John Wiley \& Sons, New York.

Overstreet, J.W. \& Cooper, G.W. (1975) Reduced sperm motility in the isthmus of the rabbit oviduct. Nature, Lond. 258, 718-719.

Overstreet, J.W. \& Cooper, G.W. (1978) Sperm transport in the reproductive tract of the female rabbit. I. The rapid transit phase of transport. Biol. Reprod. 19, $101-114$.
Overstreet, J.W. \& Katz, D.F. (1977) Sperm transport and selection in the female genital tract. In Development in Mammals, Vol. 2, pp. 31-65. Ed. M. H. Johnson. Elsevier/North Holland Bio-medical Press, Amsterdam.

Overstreet, J.W., Cooper, G.W. \& Katz, D.F. (1978) Sperm transport in the reproductive tract of the female rabbit. Il. The sustained phase of transport. Biol. Reprod. 19, 115-132.

Salomy, M. \& Harper, M.J.K. (1971) Cyclical changes of oviduct motility in rabbits. Biol. Reprod. 4, 185194.

Spilman, C.H. \& Wilks, J.W. (1976) Peripheral plasma progesterone during egg transport in rabbits. Proc. Soc. exp. Biol. Med. 151, 726-729.

Talo, A. (1974) Electric and mechanical activity of the rabbit oviduct in vitro before and after ovulation. Biol. Reprod. 11, 335-345.

Turnbull, K.E. (1966) The transport of spermatozoa in the rabbit doe before and after ovulation. Aust. $J$. biol. Sci. 19, 1095-1099.

Waterston, J.W. \& Milis, T.M. (1976) Peripheral blood steroid concentration in preovulatory rabbit. $J$. Steroid Biochem. 7, 15-17.

Yanagimachi, R. \& Chang, M.C. (1963) Sperm ascent through the oviduct of the hamster and rabbit in relation to the time of ovulation. J. Reprod. Fert. 6, 413-420.

Yanagimachi, R. \& Mahi, C.A. (1976) The sperm acrosome reaction and fertilization in the guinea pig: a study in vivo. J. Reprod. Fert. 46, 49-54.

Received 4 April 1978 